\title{
Lessons from Temporary Telemedicine Initiated owing to Outbreak of COVID-19
}

\author{
Hun-Sung Kim ${ }^{1,2}$ \\ 'Department of Medical Informatics, College of Medicine, The Catholic University of Korea, Seoul, Korea \\ ${ }^{2}$ Department of Endocrinology and Metabolism, College of Medicine, The Catholic University of Korea, Seoul, Korea
}

Following the occurrence of COVID-19 (coronavirus disease 2019) in China [1], the incidence of the disease has begun to rise in Korea [2,3], and the Ministry of Health and Welfare has allowed telemedicine for a "limited time" [4]. The temporary approval of telemedicine is intended to prevent patients becoming infected with COVID-19 during their visits to the hospital, and it is expected to make a significant contribution by preventing the spread of COVID-19 by minimizing face-to-face visits. However, because there were many controversies about telemedicine prior to COVID-19 cases $[5,6]$, even a temporary approval of telemedicine is expected to cause significant disruption.

\section{Different Purpose from the Earlier Established Evidence-Based Telemedicine}

To prepare clinical evidence in earlier telemedicine projects, various medical devices were used to check the patient's

Submitted: March 24, 2020

Accepted: April 20, 2020

\section{Corresponding Author}

Hun-Sung Kim

Department of Medical Informatics, College of Medicine, The Catholic University of Korea, 222, Banpo-daero, Seocho-gu, Seoul 06591, Korea. Tel: +82-2-2258-8262, E-mail: 01cadiz@hanmail.net (https://orcid.org/0000-0002-7002-7300)

This is an Open Access article distributed under the terms of the Creative Commons Attribution Non-Commercial License (http://creativecommons.org/licenses/by$\mathrm{nc} / 4.0 /$ ) which permits unrestricted non-commercial use, distribution, and reproduction in any medium, provided the original work is properly cited.

(C) 2020 The Korean Society of Medical Informatics condition and provide medical treatment through videotelephony [5-8]. For this reason, it is true that the earlier telemedicine projects concentrated on medical devices and platforms to check health conditions of patient $[9,10]$. In a state of emergency such as COVID-19 [11], this temporary telemedicine will definitely help. However, in the case of acute and infectious diseases such as COVID-19, the role of medical devices and platforms is ambiguous. Clear diagnosis or monitoring at home is also practically impossible. In other words, telemedicine approved at this time is not the existing evidence-based telemedicine for the purpose of healthcare itself, but most instances are simply repeated prescriptions of drugs over the phone. In other words, it is difficult to say that it is a new technology-based telemedicine utilizing new technology.

\section{Nevertheless, There Is Worry about Lack of Preparation in This Telemedicine}

From the hospital's point of view, for telemedicine, it is necessary for a nurse to first call the patients to make a reservation prior to consultation. The medical staff must call the patient again for medical consultation and then help schedule the next outpatient visit. In this process, if elderly patients do not have a good telephone connection, the telephone consultation is not executed well, and there are many communication obstacles. In the case of the elderly, it is also difficult to be sure that the person who receives the telephone consultation is actually a registered patient, and it is necessary to confirm this. From the medical staff's point of view, teleconsultation takes more time and labor than conventional 
face-to-face treatment.

From the patient's point of view, it may be necessary to visit the pharmacy again in person after telephone consultation depending on the results. It is difficult for patients to take advantage of telemedicine's ability to provide care anytime, anywhere [6]. Although it is temporary telemedicine, where only repeated prescriptions and simple comments are possible, patients have many expectations and requirements. Patients unfamiliar with telemedicine will be more interested in taking prescriptions for repeated medications without visiting the hospital, rather than using telemedicine for the purpose of healthcare.

Unlike face-to-face medical treatment, which consists of inspection, palpitation, percussion, and auscultation, telemedicine consists only of inspection; hence, safety problems and accountability are inevitable (Currently, temporary telemedicine is a telephone consultation, without inspection. Moreover, the responsibility of safety is entirely that of the medical staff). For this reason, if the medical staff focuses only on repeated medications, they may miss a relatively severe symptom that masks acute illness. It will be difficult to distinguish COVID-19 from the common cold by phone from the home of a patient who has symptoms of the common cold. Therefore, there is a risk of delaying the patient's diagnosis or missing the opportunity for adequate initial treatment. Further, service scenarios, legal reviews, scope of treatment and discretion of doctors, and insurance claims should be prepared in advance [12].

\section{Regret for Not Being Prepared in Advance}

Medical staff should not just blindly refuse telemedicine and only insist on face-to-face treatment. In any event, during the COVID-19 outbreak, telemedicine must be accepted for a limited time to reduce face-to-face contact. Unfortunately, even in the medical field, if we have had prior experience with telemedicine, or if we have been prepared accordingly for the introduction of telemedicine in advance [13], we may be able to respond more flexibly in this outbreak of COVID19.

Repeated medication prescriptions to reduce in-hospital infections are also a big advantage of telemedicine. However, it is difficult to judge whether telemedicine should be adopted in the future based only on the experience of temporary telemedicine initiated during COVID-19. Rather, attributing an exaggerated meaning to telemedicine would only raise opposition to the adoption of telemedicine in the future. Due to the sudden implementation of ill-equipped telemedicine, there are multiple concerns about poor operation. However, the time has come to seriously consider allowing remote medical care. I hope that this will be an opportunity to form a social infrastructure and consensus through the experience of temporary telemedicine adoption due to COVID-19. The aspect of national policy is definitely the most important point. Further, it is also expected that the medical field and patients need deep attention.

\section{Conflict of Interest}

No potential conflict of interest relevant to this article was reported.

\section{Acknowledgments}

This work was supported by the Technology development Program (No. S2726209) funded by the Ministry of SMEs and Startups, Korea.

\section{ORCID}

Hun-Sung Kim (http://orcid.org/0000-0002-7002-7300)

\section{References}

1. Velavan TP, Meyer CG. The COVID-19 epidemic. Trop Med Int Health 2020;25(3):278-80.

2. Yoo JH. Will the third wave of coronavirus disease 2019 really come in Korea? J Korean Med Sci 2020;35(10):e110.

3. Lim J, Jeon S, Shin HY, Kim MJ, Seong YM, Lee WJ, et al. Case of the index patient who caused tertiary transmission of COVID-19 infection in Korea: the application of Lopinavir/Ritonavir for the treatment of COVID-19 infected pneumonia monitored by quantitative RT-PCR. J Korean Med Sci 2020;35(6):e79.

4. Ministry of Health and Welfare. Temporary allowance of telephone consultation/prescription and proxy prescription [Internet]. Sejong, Korea: Ministry of Health and Welfare; 2020 [cited at 2020 Apr 15]. Available from: http://www.mohw.go.kr/react/al/sal0101vw.jsp?PAR MENU_ID $=04 \& M E N U \_I D=040102 \& C O N T$ SEQ $=$ 353269.

5. Kim HS, Cho JH, Yoon KH. New directions in chronic disease management. Endocrinol Metab (Seoul) 2015; 30(2):159-66.

6. Kim HS, Kim H, Lee S, Lee KH, Kim JH. Current clinical status of telehealth in Korea: categories, scientific ba- 
sis, and obstacles. Healthc Inform Res 2015;21(4):24450.

7. Tuckson RV, Edmunds M, Hodgkins ML. Telehealth. N Engl J Med 2017;377(16):1585-92.

8. Weinstein RS, Krupinski EA, Doarn CR. Clinical Examination component of telemedicine, telehealth, mHealth, and connected health medical practices. Med Clin North Am 2018;102(3):533-44.

9. Majumder S, Deen MJ. Smartphone sensors for health monitoring and diagnosis. Sensors (Basel) 2019;19(9): 2164.
10. Shan R, Sarkar S, Martin SS. Digital health technology and mobile devices for the management of diabetes mellitus: state of the art. Diabetologia 2019;62(6):877-87.

11. Greenhalgh T, Wherton J, Shaw S, Morrison C. Video consultations for covid-19. BMJ 2020;368:m998.

12. Clark PA, Capuzzi K, Harrison J. Telemedicine: medical, legal and ethical perspectives. Med Sci Monit 2010; 16(12):RA261-72.

13. Hollander JE, Carr BG. Virtually Perfect? Telemedicine for Covid-19. N Engl J Med 2020;382(18):1679-81. 